\title{
Preguntas frecuentes sobre la irradiación de los alimentos
}

Autora: Christine M. Bruhn, Ph.D; Traducción: Daniela Garaiz.

\section{¿POR QUÉ DEBERÍAN INTERESARME LOS ALIMENTOS IRRADIADOS?}

La irradiación mejora la seguridad y calidad de los alimentos. Aunque el abastecimiento de alimentos ha alcanzado un alto nivel de seguridad, existen riesgos. Los Centros para el Control y la Prevención de Enfermedades estiman que 76 millones de casos de enfermedad, 325,000 hospitalizaciones y 5,000 muertes ocurren cada año debido a enfermedades alimentarias. Aunque todos corremos el riesgo, los niños, personas mayores de 55 años, diabéticos, o individuos con deficiencias inmunológicas son especialmente vulnerables.

La irradiación proporciona protección contra enfermedades alimentarias que no se puede obtener por otros medios. Aun cuando la carne, aves y huevos se preparan bajo las medidas sanitarias más avanzadas posibles, pueden estar presentes bacterias dañinas. La irradiación proporciona al consumidor una protección adicional, destruyendo $99.9 \%$ ó más de E. coli O157: H7, Salmonella, Campylobacter, Listeria y otras bacterias nocivas que puedan estar presentes en alimentos crudos.

Frutas tropicales de muy buena calidad pueden enviarse a California y a otros estados gracias a que la irradiación destruye moscas de la fruta nocivas, como la mosca mediterránea, antes de que se conviertan en una plaga.

La irradiación aumenta la vida útil de varios alimentos frescos ya que retarda la maduración de las frutas y evita que las papas y cebollas germinen. Las especias y hierbas han sido fumigadas para mayor seguridad. La irradiación puede sustituir la fumigación química, produciendo especias y hierbas seguras y de alta calidad.

La Administración de Alimentos y Medicamentos de EE.UU. (FDA) aprobó el uso de la irradiación para aumentar la seguridad de germinados frescos, ya que es capaz de destruir las bacterias nocivas que pueden encontrarse bajo la semilla del germinado. La FDA quizá también autorice pronto la irradiación de carnes frías y otros alimentos listos para consumirse, ya que ese proceso puede incrementar la seguridad de dichos alimentos perecederos preempacados.

\section{¿QUÉ ES LA IRRADIACIÓN DE ALIMENTOS?}

La irradiación somete los alimentos a energía ionizante durante un tiempo específico, dependiendo del propósito del tratamiento. Dicho tratamiento complementa las buenas prácticas de manufactura y aumenta la seguridad general de los alimentos.

Los alimentos se irradian en una instalación procesadora especial donde se exponen a un haz de electrones, o rayos $\mathrm{X}$, generado por electricidad o rayos gama producidos a partir de cobalto 60. Los alimentos son monitoreados para asegurar un nivel exacto de tratamiento.

\section{¿SON SEGUROS LOS ALIMENTOS IRRADIADOS?}

Sí. Los alimentos irradiados son seguros y saludables. Después de evaluar cientos de estudios acerca de los efectos de la irradiación en la seguridad y calidad de los alimentos, los científicos de la Administración de Alimentos y Medicamentos y del Departamento de Agricultura de EE.UU. y de organizaciones de salud como la Organización Mundial de la Salud, la Asociación Médica Norteamericana y la Asociación Norteamericana contra la Diabetes, han respaldado la seguridad de los alimentos irradiados. Para asegurar su salud, los astronautas han estado consumiendo alimentos irradiados desde el inicio del programa espacial.

\section{¿CAUSA LA IRRADIACIÓN DAÑO A LOS CRO- MOSOMAS, CÁNCER, TUMORES U OTROS PROBLEMAS DE SALUD?}

No. La FDA ha estado evaluando la irradiación durante 40 años y ha concluido que el proceso es seguro. Varios estudios científicos realizados en todo el mundo confirman claramente que no existen problemas de salud o toxicidad relacionados con la irradiación.

\section{¿HACE LA IRRADIACIÓN RADIACTIVOS A LOS ALIMENTOS?}

No. Durante el proceso de irradiación, los alimentos se mueven a través de un campo energético, pero nunca

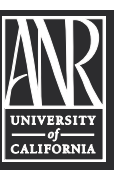

Universidad de California

División de Agricultura y Recursos Naturales

Publicación $\mathbf{7 2 6 5}$

(Spanish version of Publication 7255 ,

"Frequently Asked Questions about Food Irradiation") 
tocan la fuente de energía y no se vuelven radiactivos. La cantidad de energía y el tipo de radiación utilizada para irradiar alimentos es suficiente para matar bacterias alimentarias, pero no para hacer que los alimentos se vuelvan radiactivos, de la misma forma que el equipaje no se vuelve radiactivo al pasar por una caseta de seguridad en el aeropuerto.

Varios objetos comunes como motas de algodón, vendas adhesivas, biberones y artículos médicos se irradian por seguridad. Ninguno se vuelve radiactivo.

\section{¿DEBO MANEJAR LOS ALIMENTOS IRRADIA- DOS DE MANERA DIFERENTE A LOS OTROS ALIMENTOS?}

No. Los alimentos irradiados se manejan como cualquier otro alimento perecedero. Aunque la irradiación destruye un muy alto porcentaje de bacterias nocivas, reduce, pero no destruye, todas las bacterias que echan a perder los alimentos. Las carnes y aves deben refrigerarse para retardar el crecimiento de estas bacterias y mantener la calidad de los alimentos. La irradiación no deja ningún residuo químico en los alimentos, por lo que éstos podrían contaminarse accidentalmente después del tratamiento; es por eso que deberán manejarse y prepararse de forma adecuada para garantizar su seguridad.

\section{SI AL COCINAR BIEN LOS ALIMENTOS SE DESTRUYEN LAS BACTERIAS NOCIVAS, ¿CUÁL ES LA VENTAJA DE LAS CARNES Y AVES IRRADIADAS?}

La irradiación destruye las bacterias nocivas antes de que lleguen a la cocina. Comer alimentos irradiados reduce las enfermedades alimentarias causadas por contaminación cruzada accidental o por cocinar a temperaturas demasiado bajas. La irradiación de los alimentos proporciona a los consumidores un nivel adicional de protección.

\section{¿CONSERVAN SUS PROPIEDADES NUTRITI- VAS LOS ALIMENTOS IRRADIADOS?}

Los alimentos irradiados son nutritivos y sabrosos. Los cambios nutritivos causados por la irradiación de los alimentos son menores o comparables a los producidos al cocinar o congelar los alimentos. El contenido de tiamina se reduce al irradiar la carne de cerdo y algo de vitamina A se pierde al irradiar los huevos; sin embargo, la diferencia es tan pequeña que no afecta la alimentación de los estadounidenses.

Los cambios en el valor nutritivo de frutas y verduras son insignificantes. Algunas frutas irradiadas pueden ser hasta más nutritivas y sabrosas ya que se les permite madurar en el árbol por más tiempo que a aquéllas tratadas con otros métodos de prevención contra el transporte accidental de insectos tropicales.

\section{¿ESTÁ APROBADA POR EL GOBIERNO LA IRRADIACIÓN DE ALIMENTOS?}

La irradiación de alimentos ha sido aprobada por la Administración de Alimentos y Medicamentos de EE.UU. después de una revisión exhaustiva de seguridad alimentaria. La irradiación es la tecnología alimentaria más estudiada en la historia de Estados Unidos. Los científicos de la FDA han evaluado numerosos estudios que examinan la seguridad y el valor nutritivo de los alimentos irradiados. El Departamento de Agricultura de EE.UU. ha evaluado y aprobado la irradiación de carnes y aves. La irradiación de alimentos ha sido aprobada por más de 40 países de todo el mundo y su seguridad está respaldada por la Organización Mundial de la Salud.

\section{¿CÓMO SÉ QUE LOS ALIMENTOS HAN SIDO IRRADIADOS?}

Los alimentos irradiados tienen el logo distintivo:

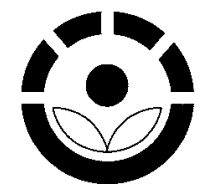

y la palabra "Irradiado" (Irradiated) en el empaque. Algunos también pueden describir el proceso como "pasteurización en frío" o "pasteurización electrónica" para mayor comprensión del consumidor.

\section{¿SE PROTEGE LA SEGURIDAD DE TRABA- JADORES Y COMUNIDADES EN LAS INSTALA- CIONES DE IRRADIACIÓN DE ALIMENTOS?}

Sí. Las instalaciones donde se realiza la irradiación están estrictamente reguladas. Las instalaciones que usan rayos gama deben estar construidas a prueba de temblores y otros desastres naturales sin poner en peligro a las comunidades vecinas ni a los trabajadores. Las instalaciones que utilizan haces de electrones y rayos $\mathrm{X}$ deben seguir los mismos lineamientos que los hospitales. Los trabajadores están entrenados para operar de manera segura el equipo de irradiación, y su seguridad personal se protege mediante un sistema multifacético de protección al i interior de la planta. Las compañías deben cumplir con los requerimientos de los gobiernos locales y estatales, así como los estipulados por la Agencia de Protección Ambiental, la Administración de Salud y Seguridad Ocupacional y el Departamento de Transporte de los Estados Unidos.

\section{¿QUIÉN DICE QUE LOS ALIMENTOS IRRADIA- DOS SON SEGUROS?}

- Administración de Alimentos y Medicamentos de EE.UU

- Departamento de Agricultura de EE.UU

- Asociación Médica Norteamericana 
- Asociación Dietética Norteamericana

- Centros para el Control y la Prevención de Enfermedades

- Organización Mundial de la Salud

- Servicio de Salud Pública de EE.UU

- Asociación Norteamericana de Salud Pública

- Asociación de Salud Ambiental de California

y muchos más

\section{¿DÓNDE PUEDO OBTENER MÁS INFOR- MACIÓN ACERCA DE LA IRRADIACIÓN DE LOS ALIMENTOS?}

Para mayor información, visite los sitios de Internet siguientes, o llame al Centro de Investigación del Consumidor al 530-752-2774. En cada sitio, haga clic en "food irradiation" o de ser necesario, teclee "irradiation" en el cuadro de búsqueda.

http://www.extension.iastate.edu/foodsafety/rad/

http://ccr.ucdavis.edu

http://www.cdc.gov

http://www.fda.gov/search.html

http://www.health.state.mn.us

http://www.ific.org/food/safety.vtml

(Haga clic en "Preguntas y Respuestas acerca de la Irradiación de Alimentos")

\section{ORDERING INFORMATION}

To order this publication or other products, visit our online catalog at http:/ / anrcatalog.ucdavis.edu. You can also place orders by mail, phone, or fax, or request a printed catalog of publications, slide sets, and videos from

University of California

Agriculture and Natural Resources

Communication Services

6701 San Pablo Avenue, 2nd Floor

Oakland, California 94608-1239

Telephone: 800-994-8849 or 510-642-2431

FAX: 510-643-5470

E-mail inquiries: danrcs@ucdavis.edu

For a free catalog of other publications, telephone (800) 994-8849.

Visit the ANR Communication Services website at http://anrcatalog.ucdavis.edu.

\section{Publication 7265}

(C) 2004 by the Regents of the University of California,Division of Agriculture and Natural Resources. All rights reserved.

La Universidad de California prohibe la discriminación o el hostigamiento de cualquier persona empleada o aspirante a empleo en la Universidad de California. Esta prohibición abarca razones de raza, color, origen nacional, religión, sexo, incapacidad física o mental, estado de salud (casos de cáncer o de características genéticas), ascendencia, estado civil, edad, orientación sexual, ciudadanía o condición de veterano (veterano con incapacidad específica, veterano de la era de Vietnam o cualquier veterano que haya estado en servicio activo en una guerra, campaña o expedición para la cual una insignia de campaña haya sido autorizada). La política de la Universidad se propone concordar con las disposiciones de las leyes federales y estatales procedentes. Las preguntas sobre la política antidiscriminatoria de la Universidad pueden dirigirse a: The Affirmative Action/Staff Personnel Services Director, University of California, Agriculture and Natural Resources, 300 Lakeside Drive, 6th Floor, Oakland, CA 94612-3550; (510) 987-0096.

pr-9/04-WJC

ISBN 978-1-60107-056-2 